\title{
La competencia legislativa en materia de cooperativas: el caso español
}

\author{
Dr. Enrique Gadea Soler \\ Universidad de Deusto
}

Sumario: 1. Delimitación material de la competencia legislativa en materia de cooperativas después de la Constitución de 1978. 2. Delimitación territorial de la competencia legislativa en materia de cooperativas. 2.1. La etapa anterior a la vigente la Ley $27 / 1999$ de Cooperativas. 2.2. El nuevo criterio introducido por la Ley 27/1999. 3. La competencia estatal sobre las bases de la ordenación de la actividad crediticia y aseguradora.

Resumen: El presente trabajo tiene por objeto analizar la delimitación material de la competencia legislativa en materia de cooperativas después de la Constitución de 1978, así como la delimitación territorial de la competencia legislativa tanto en la etapa anterior a la vigente Ley 27/1999 de Cooperativas como en la actualidad. Finaliza con una referencia a la competencia estatal sobre las bases de la ordenación de la actividad crediticia y aseguradora.

Palabras clave: Las Cooperativas: competencia legislativa y territorial.

Abstract: This paper aims to examine the material scope of legislative competence with regard to cooperatives after the 1978 Constitution, as well as the territorial scope of legislative competence both in the stage prior to the current Law 27/1999 on Cooperatives and at present. It ends with a reference to state competence on the basis of the organisation of credit and insurance activity.

Keywords: Cooperatives: regulatory and territorial competence. 


\section{Delimitación material de la competencia legislativa en materia de cooperativas después de la Constitución de 1978}

En la actualidad no existe una única Ley sino varias Leyes de cooperativas, dado que la mayoría de los territorios tienen norma propia. Para explicar esta situación debe tomarse como punto de partida la nueva organización territorial del Estado que arbitra la Constitución de 1978. Se trata de un sistema de organización territorial autóctono, Ilamado «Estado de las Autonomías», que presenta similitudes con un Estado federal, aunque también no pocas diferencias. Con él, se divide España en 17 Comunidades Autónomas, distribuyéndose las competencias entre éstas y el Estado. La propia Constitución dedica dos artículos a la distribución de competencias: el 148 se refiere a las competencias que pueden asumir las Comunidades Autónomas en sus respectivos Estatutos; y el 149 recoge las competencias sobre las que el Estado se reserva la competencia exclusiva, entre ellas —en el párrafo 1.6 - se señala la relativa a la Legislación mercantil.

Aprovechando la imprecisión existente sobre la calificación y el encuadramiento de la sociedad cooperativa, para la que todavía hay que recurrir al obsoleto artículo $124 \mathrm{CDC}^{1}$, los Estatutos de Autonomía del País Vasco (artículo 10.23) y de Cataluña (artículo 9.21) atribuyen a sus Comunidades Autónomas competencia exclusiva en materia de cooperativas. Posteriormente, también asumen competencias legislativas exclusivas en esta materia el Estatuto para Andalucía (artículo 13.20), el Estatuto de la Comunidad Valenciana (artículo 31.21) y la Ley reguladora del Régimen Foral de Navarra (artículo 44.7).

Sobre la base a la competencia asumida por los respectivos Estatutos de Autonomía, el legislador vasco primero - mediante la Ley 1/1982, de 22 de febrero-, y posteriormente el catalán —a través de la Ley 1/1983, de 9 de marzo-, aprueban sus respectivas Leyes de cooperativas.

Ley vasca fue objeto de recurso de inconstitucionalidad, con el que el Estado puso en entredicho la constitucionalidad de toda la delimita-

1 En la actualidad a una sociedad de carácter esencialmente mutualista y fuertemente personalista como la sociedad de garantía reciproca se le atribuye expresamente carácter mercantil (artículo 4 de la Ley 1/ 1994, de 11 de marzo, sobre régimen jurídico de las sociedades de garantía reciproca), por ser lo más adecuado para una eficaz organización. En cambio, el Código de comercio supedita la aplicación de sus normas a si la sociedad se dedica o no a "actos de comercio extraños a la mutualidad». 
ción competencial en materia de cooperativas, aunque no contribuyó a modificar la situación previamente creada.

El recurso se resuelve en la sentencia 72/83, de 29 de julio. De ella se desprende que "... las partes centran el debate de la competencia legislativa del País Vasco (y por tanto de las demás Comunidades que han asumido competencia exclusiva) en la consideración del denominado Derecho cooperativo como una parte o no del Derecho mercantil. La trascendencia que otorgan a esta configuración se explica fácilmente porque la Constitución establece que el Estado tiene competencia exclusiva en materia de Legislación mercantil (artículo 149.1.6) y el Estatuto atribuye competencia exclusiva al País Vasco en materia de cooperativas «conforme a la Legislación general en materia mercantil» (artículo 10.23), por lo que si la regulación sobre cooperativas hubiera de calificarse de mercantil — como sostiene el Abogado del Estado— la conclusión a la que habríamos de llegar sería la de que la competencia legislativa en materia de cooperativas no corresponde a la Comunidad Autónoma».

No obstante, el Tribunal, sin entrar en el fondo del asunto y sin tener en cuenta que aunque la cooperativa se calificase como sociedad civil la competencia también correspondería al Estado sobre la base del artículo 149.1.8, señala que: «...sin pretender ahora sentar afirmaciones de carácter general... si podemos afirmar que en principio no es admisible una interpretación que conduzca a variar de contenido la competencia legislativa de la Comunidad en materia de cooperativas, que hay que entender le viene atribuida por el artículo 10.23 del Estatuto».

A esta conclusión: "...conduce la interpretación sistemática de los preceptos de la Constitución y del Estatuto, situado en el marco constitucional, y que prescinde de cualquier posición doctrinal acerca de si las cooperativas han de calificarse o no como sociedades mercantiles, ya que la interpretación ha de situarse en el contexto del ordenamiento vigente» (fundamento jurídico 3. ${ }^{\circ}$ ).

En principio, sólo las cinco Comunidades referidas asumieron competencia legislativa exclusiva, aunque, en la actualidad, todas las Comunidades tienen transferida la competencia en la materia: mediante la Ley Orgánica 9/92, de 23 de diciembre, se transfirió la competencia a Asturias, Cantabria, La Rioja, Murcia, Aragón, Extremadura, Baleares, Madrid, Castilla-La Mancha y Castilla-León, Galicia recibe la transferencia través de la Ley Orgánica 16/95 y, finalmente, Canarias mediante la Ley Orgánica 4/96, de 30 de diciembre.

Como consecuencia de esta delimitación territorial de competencias en materia de cooperativas, nos encontramos con una Ley gene- 
ral de cooperativas, 3/1987 de 2 de abril, que se aplicará en aquellas Comunidades Autónomas que no han aprobado Ley de cooperativas y de forma supletoria en las Comunidades con norma propia, y con las Leyes propias de las Comunidades que las han aprobado: Ley 1/1982, de 22 de febrero de cooperativas del País Vasco, Ley 4/1983, de 9 de marzo, de cooperativas de Cataluña, Ley 2/1985, de 2 de Mayo, de cooperativas de Andalucía, Ley 11/1985, de 25 de Octubre, de cooperativas de la Comunidad Valenciana, Ley foral 12/1989, de 3 de Julio, de cooperativas de Navarra. La aprobación de las demás, y la reforma de las leyes citadas, se realizará en fecha más reciente, tal como señalaremos posteriormente.

A la hora de valorar esta situación encontramos serios recelos, como el de Borjabad², cuando apunta: «... el observador empieza a preguntarse si ha sido necesaria, y sobre todo si lo es, y si va a seguir siendo conveniente, tal fragmentación de la Legislación cooperativa en un Estado de poco más de cuarenta millones de habitantes, o si tal situación va a ser el origen de un caos, donde en el mejor de los casos, una norma autonómica no va a tener más valor que el que podía suponer en otra época una de carácter estatutario» y con duras críticas como la de I. Arroyo ${ }^{3}$ cuando señala : "La ciencia jurídica dispone de técnicas legislativas depuradas para dar solución adecuada a problemas políticos, sin menoscabo del rigor científico de la materia regulada. No es moneda de uso corriente, en la actual sociedad democrática española, navegar en contra de las potestades legislativas de las Comunidades Autónomas. Nadie puede negar que el movimiento cooperativo histórica, sociológica y económicamente, ha prendido con más fuerza entre las poblaciones asentadas en las hoy llamadas Comunidades Autónomas. El movimiento catalán cooperativo es un dato histórico de singular importancia, la estructura cooperativa vasca domina buena parte de la organización económica euskaldún, las cooperativas ganaderas gallegas presentan cifras de facturación homologables a empresas multinacionales, y las cooperativas agrícolas andaluzas pueden ser el fermento de la expansión económica de toda la región. No nos engañemos, el poder central no puede ser insensible a la evidencia. En pocas palabras, la cooperación hunde sus raíces en una estructura política regional, formalista o cantonal. Ahora bien, si el político no puede volver la espalda a la realidad, la política legislativa tampoco puede olvidar que las disciplinas jurídicas tienen sus lí-

2 «Reforma de la Legislación cooperativa con especial referencia a Cataluña», en Noticias de la economía pública social y cooperativa, n. ${ }^{\circ} 14$, p. 51.

3 Legislación sobre cooperativas, 3. ${ }^{a}$ ed., Tecnos, Madrid, 1992, pp. 15 y 16. 
mites, que tampoco es bueno soslayar. Por todo ello me parece más acertado que el Estado central se hubiera reservado - como creo que manda la propia Constitución- la competencia legislativa exclusiva en todo el territorio nacional, bien por el cauce de la ley de bases o mejor aún por el texto articulado, dejando para las Comunidades ya el desarrollo articulado, ya la potestad reglamentaria. En la peor hipótesis se hubiera respetado el esfuerzo de la doctrina científica, y en la más favorable se habría evitado tanto alarde legislativo y tanta reiteración».

Las palabras del profesor I. Arroyo cobran si cabe mayor fuerza al analizar la postura mayoritaria que se adopta respecto al término «Legislación mercantil». J.F. Duque ${ }^{4}$ afirma que no puede reducirse al contenido del Código de comercio o, aplicando un principio de subrogación legislativa, a las normas que hubiesen sucedido, por la vía de reforma legislativa, a los originarios preceptos del Código. Es casi inoportuno recordar - apunta- que el Código de comercio se constituye como un ordenamiento abierto, en el que la actividad de la sociedad puede incluir normas nuevas para regular las nuevas instituciones que vayan surgiendo de la práctica social. En el mismo sentido, A. Menénde $z^{5}$ señala que la expresión «Legislación mercantil» no puede quedar reducida al contenido del Código de comercio vigente o a las normas que hubiesen sucedido, por vía de reforma legislativa a las materias comprendidas en el mismo. No es fácil compartir alguna autorizada opinión ${ }^{6}$ en el sentido de que la expresión «Legislación mercantil» se corresponda básicamente con la noción tradicional del Derecho mercantil, vinculada al contenido del Código de comercio, y dejar fuera de ella materias que han surgido legislativamente con independencia del Derecho mercantil tradicional y que han sido incluidas dentro de esa rama del ordenamiento jurídico por la doctrina científica de los últimos tiempos. Dentro del Derecho mercantil vivo — continúa señalando el autor ${ }^{7}$ - es decir, el que prolifera al margen de la codificación, debemos destacar el moderno Derecho de la organización industrial, los nuevos tipos de empresa, las variadas fórmulas de concentración em-

4 «Constitución económica y Derecho mercantil», en La reforma de la Legislación mercantil, Fundación Universidad-Empresa, Civitas, Madrid, 1979, pp. 77 y ss.

5 Constitución, sistema económico y Derecho mercantil, Civitas, Madrid, 1982, pp. 73 y ss.

6 Bercovitz, A.: Actualizaciones de Derecho mercantil, Vol. I, UNED, Madrid, 1981, p. 11.

7 Menéndez, A.: Código de comercio y reforma de la Legislación mercantil, cit., pp. 49 y 50 . 
presarial, el desarrollo del sector y de las empresas públicas, la importancia creciente de la propiedad industrial, el nuevo tratamiento de la contabilidad y la información, el ordenamiento de la libre competencia y las prácticas restrictivas, la difusión de la propiedad mobiliaria, la inversión institucional y colectiva, los cambios producidos en los instrumentos de crédito, las nuevas formas de distribución comercial y dentro de este contexto y, por tanto, dentro del Derecho mercantil vivo también considera que debe encuadrarse lo que a nosotros principalmente nos interesa destacar, el Cooperativismo.

Llegado a este punto, nos parece importante resaltar que es cierto, como señalábamos al principio, que para el legislador de 1885 el Derecho mercantil es el Derecho de los actos, actividades e instituciones especulativas o capitalistas en el que no tienen cabida las asociaciones económicas de la clase obrera ${ }^{8}$, aunque no lo es menos que, en la actualidad, está concepción resulta inadecuada. Tal como señala M. Vergez ${ }^{9}$, ni el Código de comercio puede considerarse como expresión propia de la mercantilidad, ni tampoco es - o debe ser- correcta la equiparación entre el Derecho mercantil y el capitalismo. La identificación del Derecho mercantil como derecho del capitalismo tiene en nuestro país importantes valedores ${ }^{10}$, pero por ello no debe renunciarse a superarla mediante la aplicación a instituciones tradicionalmente consideradas no capitalistas, de un conjunto de normas que son necesarias para la propia solvencia de la entidad, para garantía de los terceros $y$, en definitiva, para atender las exigencias de una actividad económica profesional en torno al mercado. Es evidente que muchas figuras mercantiles han encontrado su auge y desarrollo en el seno de una economía capitalista, propia de un capitalismo liberal, para darse cuenta de ello basta con dar una ojeada al famoso libro de Ripert «Aspectos jurídicos del capitalismo moderno». Pero no por ello ha de considerarse que el Derecho mercantil deba ser siempre identificado con el Derecho del capitalismo. Al margen de la realidad normativa de un Código decimonónico como el nuestro, el Derecho mercantil actual (es decir, el conjunto de normas de la nueva clase social de la Edad Media que, posteriormente, se generalizan) debe ser un derecho de los profesionales del tráfico económico, que se ha sensi-

8 De hecho nuestro Código partió de una concepción radical capitalista de la empresa. Sobre este punto resulta interesante el artículo de BROSETA, M., "La reforma de la empresa en el sistema capitalista español», RDM, 1970, pp. 265 y ss.

9 «Significado y encuadramiento de la sociedad cooperativa en el Derecho español», Tribuna Cooperativa, nums. 40-41, 1980.

10 RUBIO, J.: «Sobre el concepto de Derecho mercantil», RDM, 1947, p. 358. 
bilizado, como no podía ser de otro modo, a la nueva problemática económica y social ${ }^{11}$.

En este sentido, consideramos conveniente insistir que en el ámbito del Derecho mercantil se ha producido, como señala A. Menéndez ${ }^{12}$, lo que se ha dado en llamar "crisis de la aptitud funcional del Derecho vigente», ya que la funcionalidad del Derecho mercantil codificado se ha debilitado de modo radical ante los profundos cambios que se han operado en la realidad económica. La insatisfacción que produce el contraste entre norma y realidad ha empeñado a los científicos del Derecho mercantil en una polémica que se inicia en los albores de nuestro siglo. En buena parte toda esa discusión ha desembocado en la concepción de un Derecho mercantil que se aleja de su configuración como un Derecho de determinados actos o como un Derecho especial de las obligaciones, para convertirse en un Derecho de la economía organizada en forma de empresa. Esa es la pieza que faltaba en los cuerpos legales del siglo xIX y que podría haber dotado de unidad al sistema.

Por otra parte, también nos interesa destacar que sería absurdo afirmar que la empresa es una creación del capitalismo industrial, porque es evidente que como organización para el mercado está ya presente en la vieja organización del comerciante medieval. Con ello debe rechazarse la idea, relativamente extendida, de que el Derecho mercantil es sólo aplicable a las sociedades capitalistas. Como ha señalado el profesor Broseta ${ }^{13}$ existen dos corrientes principales en torno al concepto de empresa. En la primera, se reserva el concepto de empresa para la capitalista, la cual se caracteriza por el recurso al trabajo ajeno y por el móvil lucrativo que inspira su actividad. Frente a esta tendencia restrictiva se sitúa una más amplia, que es necesario tomar como punto de partida a la hora de analizar el Derecho mercantil moderno, que acepta la existencia de la empresa aun cuando no se persiga una fina-

11 También a este respecto cabe destacar palabras de A. PALA BERDEJo ( $E$ El Derecho mercantil y los caracteres de nuestro tiempo», Revista general de Legislación y Jurisprudencia, 1953, pp. 25 y 26) que apunta: «El sistema jurídico mercantil no implica una ideología de clases. Ciertamente nació en el comercio, con los actos económicos organizados en masa, si bien luego la técnica moderna propició y dio pábulo a su desarrollo. Su prevalencia se impone porque posibilita el progreso económico, y el progreso económico es hoy lo que primordialmente interesa, e interesa de seguro a todos, sin discriminación de clases o estamentos sociales».

12 «Código de comercio y reforma de la Legislación mercantil», en La reforma de la Legislación mercantil, Civitas, Madrid, 1979, pp. 48 y ss.

13 La empresa, la unificación del Derecho de obligaciones y el Derecho mercantil, Tecnos, Madrid, 1965, pp. 168, nota 20. 
lidad lucrativa. En efecto, como señala un sector importante de la doctrina el ánimo de lucro no es necesario para el concepto de empresa ni imprescindible para adquirir la condición de empresario ${ }^{14}$. En ambos casos basta «la economicidad de la gestión». Como ha señalado I. Arroyo ${ }^{15}$ en este sentido la ecuación mercantil-lucro ha dado paso al binomio mercantilidad-economicidad. Si bien es cierto que el espíritu de lucro ha caracterizado históricamente a quienes profesionalmente se han dedicado a ejercer el comercio, puede señalarse que jurídicamente es irrelevante. Lo que ha exigido el nacimiento de un Derecho especial no ha sido la presencia de aquel espíritu sino el hecho de que para actuarlo se ha ejercido una actividad profesional. Este espíritu o finalidad no se ha convertido en requisito esencial de la mercantilidad, como se comprueba en el artículo 277 del Código de comercio vigente, y en el hecho de reputarse mercantiles por razón de la forma las sociedades anónimas o de responsabilidad limitada independientemente de que su finalidad sea o no lucrativa. Quiere ello decir que su inexistencia no es bastante por si misma para negar la naturaleza mercantil de las instituciones, ni su presencia suficiente para afirmarla ${ }^{16}$.

Para obtener el fundamento del Derecho mercantil —con la relatividad que el término conlleva-, superada la teoría de la empresa, nos interesa destacar el aspecto de la actividad del empresario que, realizándose por medio de una empresa, plantea concretas exigencias que justifican su subsistencia como Derecho especial. Estas exigencias de la actividad económica realizada por medio de una empresa, determinan la presencia de un sujeto (empresario) peculiar respecto a los demás sujetos de Derecho, de un modo especial de realizarla, de unos métodos $y$, por tanto, de unos principios necesarios a toda actividad profesional. En principio, la presencia de una empresa y de un empresario debería bastar para calificar como mercantiles las actividades que por medio de ellos se realicen. Para no entrar en una dinámica de problemas dogmáticamente insolubles no debe aceptarse que sea la naturaleza de la actividad económica realizada por medio de una empresa la que atribuya o prive al sujeto de la condición de empresario mercantil. Ni que

14 En este sentido Llobregat, M. L.: Mutualidad y empresas cooperativas, Bosch, Barcelona, 1990, pp. 37, 38 y 121; PAZ ARES, C.: «La causa no lucrativa en la agrupación de interés económico», en Escritos jurídicos en memoria de Luis Mateo, Tomo II, Universidad de Cantabria, 1993, pp. 271.

15 Legislación sobre cooperativas, cit., p. 13.

16 BRosetA, M.: La empresa, la unificación del Derecho de obligaciones y el Derecho mercantil, cit., pp. 238 y 239. En el mismo sentido, DIVAR, J., en Régimen jurídico de las sociedades cooperativas, Universidad de Deusto, Bilbao, 1987, pp. 30 y 31. 
existan, por tanto, empresas mercantiles y otras civiles. Por el contrario, cualquier actividad de producción o mediación de bienes o servicios en relación con el mercado, realizada en forma organizada por medio de una empresa, debe atribuir a su titular la condición de empresario mercantil. En definitiva, la mercantilidad del sujeto, es decir, la aptitud para convertirse en empresario mercantil debe depender de la forma, del método o de la manera como tal actividad se realice.

Como ha señalado J. Garrigues el centro de gravedad del sistema se ha desplazado del acto a la organización. Nuestro Derecho debe liberarse definitivamente de todo problema de finalidad del acto para colocar el asunto de la comercialidad (o más bien de la aplicación de un estatuto concreto) sobre el dato objetivo y tangible de la organización en forma mercantil ${ }^{17}$. Por ello, si la explotación de aquellas actividades se hace en relación con el mercado, en forma habitual, organizada y, en definitiva, disponiendo de una empresa y utilizando los métodos mercantiles, no cabe duda de que el sujeto que la realiza deberá ser considerado empresario mercantil y deberá someterse al estatuto propio de éstos ${ }^{18}$. Como hemos visto, estas notas características las encontramos al analizar la estructura organizativa y los métodos de las sociedades cooperativas, por ello debe aplicárseles, como señalábamos en páginas anteriores, el régimen jurídico adecuado a la actividad empresarial y a la organización de la empresa y ser consideradas como sociedades mercantiles de naturaleza especial: en puridad técnica la sociedad cooperativa debe ser considerada como una fórmula jurídica para la organización económica, sujeta a los principios y fines que le son específicos ${ }^{19}$ y que tiene la misma extensión técnica y económica que puede tener una Sociedad capitalista (anónima o limitada) ${ }^{20}$.

Antes de concluir este apartado nos parece interesante recoger la opinión del Profesor A. Polo. Como es sabido, entre los maestros del Derecho mercantil, el Profesor Polo es el que prestó más atención al régimen jurídico de las cooperativas. Este en sus distintas publicaciones (ya mencionadas a lo largo de este trabajo) y, en base a sólidos argumentos, sentó la tesis, aceptable de «lege data», de que los términos

17 «Qué es y qué debe ser el Derecho mercantil», RDM, 1959, p. 32. En este sentido también ha señalado GIRÓN, J. («El concepto de Derecho mercantil», ADC, 1954, p. 802) que lo que importa es el aspecto político-jurídico condicionado por las características de la estructura económica del tipo de actividad.

18 BRoseta, M., La empresa, la unificación del Derecho de obligaciones y el Derecho mercantil, cit., pp. 283, 287 y 260.

19 Divar, J., Régimen jurídico de las sociedades cooperativas, cit., pp. 29 y 30.

20 Id, La alternativa cooperativa, cit., p. 43. 
«cooperativa» y «mercantil» eran incompatibles. No obstante, convencido del grave perjuicio que el divorcio entre las cooperativas y el Derecho mercantil ha tenido para aquéllas, en el borrador para un Anteproyecto de Ley de sociedades mercantiles que se le encargó redactar en 1968, incluiría a las sociedades cooperativas. Y en su última "Lección magistral» 21 , precisamente en 1978 , muestra la firme convicción de que las cooperativas están reclamando urgentemente el régimen jurídico de la organización de una empresa económica: el régimen jurídico mercantil. Después de señalar que: «El verdadero problema reside hoy en no poder encerrar en los moldes tradicionales del artículo 1 del CDC. la enorme tipología de los actuales titulares o sujetos de la actividad económica constitutiva de empresa...», matiza: "...se hace preciso, pues, contemplar el fenómeno de la tendencia a la ampliación del número de los titulares empresariales de la actividad económica, superando el rígido molde que hasta ahora nos brindaban el Código de comercio (arts. 1, 116 y 124) y algunas leyes especiales, para pensar en una serie de manifestaciones, algunas de ellas conocidas desde hace tiempo, de las que no cabe desoír su apremiante llamada para retornar al campo del Derecho mercantil, como, por ejemplo las sociedades cooperativas...». Es indudable que en este momento se pierde una gran oportunidad para remediar las incoherencias anteriores y para adoptar una postura más coherente sobre el futuro modelo de la Legislación sobre cooperativas.

Además de los señalados, también deben tenerse en cuenta otros argumentos para justificar que la competencia legislativa en materia de cooperativas deba corresponder al Estado. Por una parte, la existencia de diversas leyes reguladoras del régimen jurídico de las sociedades cooperativas es perjudicial para una sociedad que tiene que competir con instituciones capitalistas que tienen una regulación uniforme y difícilmente explicable ante el mandato de fomentar las sociedades cooperativas que impone el artículo 129.2 de la Constitución. Por otra, la existencia de tantas leyes de cooperativas en España va en contra de la propia lógica jurídica: las Comunidades Autónomas en materia de cooperativas no necesitan regular "ex novo» y totalmente todo lo relativo a las mismas. Ciertamente, no se ve ninguna necesidad de que materias como el concepto legal de sociedad cooperativa, los principios cooperativos y su realización legal, el régimen de los órganos de gestión y control de la cooperativa y de verificación o censura de cuentas,

21 Publicada con el título: «Reflexiones sobre la reforma del ordenamiento jurídico mercantil», en los Estudios de Derecho mercantil en homenaje a Rodrigo Uría, Madrid, 1978, pp. 578 y ss. 
el régimen del capital, las causas de disolución, el procedimiento de liquidación y el régimen jurídico aplicable en caso de insolvencia, sean distintas en cada uno de los territorios autónomos. Aún adquiere más consistencia este argumento cuando es opinión comúnmente aceptada que tampoco es conveniente que existan diferencias en relación con los aspectos citados entre la Legislación italiana, alemana o francesa, lo que ha dado lugar a propuestas en la Comisión de la Unión Europea para que se publique una Directriz en orden a uniformar el Derecho de cooperativas, como lo ha hecho con el Derecho de sociedades de capital, en sus aspectos más importantes ${ }^{22}$.

\section{Delimitación territorial de la competencia legislativa en materia de cooperativas}

\subsection{La etapa anterior a la vigente la Ley 27/1999 de Cooperativas}

Como hemos señalado anteriormente, el Tribunal Constitucional - en la sentencia 72/83- considera que las Comunidades Autónomas en que lo prevea su Estatuto tienen competencia legislativa en materia de cooperativas. Sin embargo, inmediatamente después en la misma sentencia se plantea el problema del alcance territorial de las competencias autonómicas, ya que la Disposición final $1 .^{a}$ de la Ley vasca de cooperativas establece que: "La presente Ley se aplicará a todas las cooperativas con domicilio en la Comunidad Autónoma del País Vasco, con independencia de su ámbito territorial de actuación».

El Abogado del Estado la impugna porque: «...sitúa como punto de conexión el domicilio con independencia del ámbito territorial de actuación, con lo que cabe, a su entender, que cooperativas domiciliadas en el País Vasco, pero que ejerzan íntegramente sus actividades fuera del mismo, se sujeten a la Ley impugnada, con exclusión de cualquier otra».

Para resolver esta cuestión el Tribunal considera necesario partir del artículo 20.6 del EAPV que señala: "Salvo disposición expresa en contrario todas las competencias mencionadas en los artículos anteriores y otros del presente Estatuto se entienden referidas al ámbito territorial del País Vasco».

Al interpretar esta disposición el Tribunal entiende que las relaciones de carácter cooperativo que son las que, a su juicio, determinan la

22 VICENT Chulía, F., «Los órganos sociales de la cooperativa», RJC, 1978, pp. 81 y 82. 
competencia, son las que habrán de desarrollarse en el ámbito territorial del País Vasco. Y son consideradas relaciones de carácter cooperativo las relaciones de las cooperativas con sus socios, debiendo asimilarse a ellas, como sucede en el caso previsto en el artículo 57.2 de la Ley impugnada, relativo al supuesto en que las cooperativas de consumo pueden suministrar a los no socios.

Para acabar de precisar la cuestión la Sentencia señala, además, que: «...la cooperativa como persona jurídica ha de establecer relaciones jurídicas externas con terceros que no pueden encuadrarse dentro de las «funciones» típicas de las mismas y que tienen un valor instrumental y necesario para la consecución del fin social. Así, por ejemplo, una cooperativa de consumo habrá de comprar los productos que vende a sus socios, y en determinados supuestos a terceros, y una cooperativa de producción habrá de vender lo producido. Es una actividad inherente a determinadas cooperativas el poder establecer relaciones como las señaladas, actividad que realiza exactamente igual que otra persona jurídica. La competencia material de la Comunidad respecto a las cooperativas no incide directamente en estas relaciones... Se trata, en definitiva, de actividades y relaciones instrumentales en las que la cooperativa actúa como cualquier otra persona jurídico-privada, en el ámbito territorial del País Vasco o fuera del mismo».

Como conclusión señala el Tribunal: «... la Comunidad Autónoma del País Vasco tiene competencia para regular por Ley las cooperativas que lleven a cabo su actividad societaria típica en los términos ya expuestos, dentro del territorio de la Comunidad, aun cuando establezcan relaciones jurídicas o realicen actividades de carácter instrumental fuera del territorio de la misma» (fundamento jurídico $\left.4 .^{\circ}\right)^{23}$.

\subsection{El nuevo criterio introducido por la Ley 27/1999 (LCOOP)}

La LCoOp dedica su artículo 2 a definir su ámbito de aplicación, de la siguiente manera: «La presente Ley será de aplicación: a) A las sociedades cooperativas que desarrollen su actividad cooperativizada en el territorio de varias Comunidades Autónomas, excepto cuando en una de ellas se desarrolle con carácter principal; b) A las sociedades cooperativas que realicen principalmente su actividad cooperativizada en las ciudades de Ceuta y Melilla».

23 Con posterioridad, y en relación con este tema aunque siempre partiendo de las pautas marcadas por esta sentencia, se dictaron las sentencias 44/84, de 27 de marzo, 165/1985, de 5 de diciembre y la sentencia 88/1989, de 11 de mayo. 
Recordemos que, como hemos señalado anteriormente, el TC —en la Sentencia 72/83 - considera que las CCAA en que lo prevea su Estatuto tienen competencia legislativa en materia de cooperativas. Sin embargo, inmediatamente después, en la misma sentencia se plantea el problema del alcance territorial de las competencias autonómicas, ya que la disposición final $1{ }^{\text {a }}$ de la Ley de Cooperativas del País Vasco de 1982 establecía que «la presente Ley se aplicará a todas las cooperativas con domicilio en la Comunidad Autónoma del País Vasco, con independencia de su ámbito territorial de actuación».

El Abogado del Estado la impugna porque «sitúa como punto de conexión el domicilio con independencia del ámbito territorial de actuación, con lo que cabe, a su entender, que cooperativas domiciliadas en el País Vasco, pero que ejerzan íntegramente sus actividades fuera del mismo, se sujeten a la Ley impugnada, con exclusión de cualquier otra». Para resolver esta cuestión el TC, aunque considera inconstitucional del criterio del domicilio utilizado por la Ley de vasca, introduce la distinción entre funciones típicas o relaciones de carácter cooperativo (que tienen lugar entre la cooperativa y los socios) y actividades instrumentales (de carácter necesario para la consecución del fin social) y entiende que las relaciones típicas o de carácter cooperativo que son las que, a su juicio, determinan la competencia, son las que habrán de desarrollarse en el ámbito territorial del País Vasco. Por tanto, según el TC, las CC.AA. tienen competencia para regular por Ley, las cooperativas que lleven a cabo su actividad societaria típica en los términos ya expuestos, dentro del territorio de la Comunidad, aun cuando establezcan relaciones jurídicas o realicen actividades de carácter instrumental fuera del territorio de la misma (Fundamento Jurídico 4. ${ }^{\circ}$ ).

Sin embargo, la LCoop, a diferencia de la LGC de 1987, siguiendo el criterio de delimitación espacial utilizado por la mayoría de leyes de cooperativas autonómicas, declara que sólo es aplicable a las cooperativas que desarrollen su actividad cooperativizada en el territorio de varias Comunidades Autónomas, excepto cuando en una de ellas se desarrolle con carácter principal24.

24 La disposición final 1. ${ }^{a}$ LGC excluía de su ámbito de aplicación a las sociedades cooperativas «cuyas relaciones de carácter cooperativo interno que resulten definitorias del objeto social cooperativizado, y entendiéndose por tales relaciones las de la cooperativa con sus socios se lleven a cabo dentro del territorio de una Comunidad Autónoma». En Canadá, con una situación territorial y competencial en materia de cooperativas similar a la española, con una ley nacional (Ley de Cooperativas de Canadá de 1999) y varias leyes provinciales, aquélla es de aplicación a las cooperativas que tiene un ámbito superior a una provincia (art. 3.2). 
Como resultado de esta delimitación territorial de competencias en materia de cooperativas, nos encontramos, de un lado, con una Ley estatal, que ya no tiene aplicación general como sus predecesoras sino fundamentalmente supletoria; y de otro, con las leyes cooperativas de las distintas Comunidades Autonómicas, que siguen, aunque con diferencias, similar ámbito de aplicación de sus normas ${ }^{25}$, y que pasamos a citar, sin perjuicio que, fecha de hoy, alguna de ellas ya haya sido nuevamente modificada:

Ley 4/1993 de Cooperativas del País Vasco (LCPV), que deroga la Ley 1/1982; Ley 2/1998 de Sociedades Cooperativas de Extremadura (LCEEx); Ley 9/1998 de Sociedades Cooperativas de Aragón (LCAr), muy modificada por la Ley 4/2010; Ley 5/1998 de Cooperativas de Galicia (LCG); Ley 4/1999 de Cooperativas de la Comunidad de Madrid (LCCM); Ley 4/2001 de Cooperativas de la Rioja (LCLR); Ley 18/ 2002 de Cooperativas de Cataluña (LCCat), que sustituye al Texto Refundido aprobado por Decreto Legislativo 1/1992; Ley 4/2002 reguladoras de las Cooperativas de Castilla y León (LCCL); Ley 8/2003 de Cooperativas de la Comunidad Valenciana (LCCV), que deroga el Texto Refundido aprobado por el Decreto Legislativo 1/1998; Ley 1/2003 de Cooperativas de las Islas Baleares (LCIB); Ley 8/2006 de Cooperativas de la Región de Murcia (LCMur); Ley Foral 14/2006 de Cooperativas de Navarra (LFCN), que sustituye a Ley 12/1996; Ley 11/2010 de Cooperativas de Castilla-La Mancha (LCCLM), que deroga a la Ley 20/2002; Ley 4/2010 de Cooperativas del Principado de Asturias (LCPA); Ley 14/2011 de Sociedades Cooperativas Andaluzas (LCAnd), que deroga a la Ley 2/1999 que, a su vez, sustituyó a la Ley 2/1985; y Ley 6/2013 de Cooperativas de Cantabria (LCCan). En Canarias, única Comunidad sin Ley de cooperativas, se publicó en noviembre de 2013 el Proyecto de Ley de Socie-

25 Inexplicablemente no hay plena coincidencia entre la determinación del ámbito de aplicación de la ley estatal y las autonómicas de cooperativas, ya que si bien la LCoOP y algunas e las principales leyes autonómicas sólo exigen para la aplicación de la ley autonómica que la cooperativa desarrolle en ella principalmente (mayoritariamente dicen algunas veces) la actividad cooperativizada (art. 1 LCVV, art. 2.2 LCCAT, disp. final 2. ${ }^{a}$ LCPV) societaria (art. 3 LCAND); en otras leyes, para que sea de aplicación la ley autonómica la cooperativa debe desarrollar en dicha comunidad toda la actividad con sus socios, sin perjuicio de la actividades instrumentales o accesorias que pueden desarrollarse fuera (art. 1 LCAR, art. 1 LCEx, art. 2 LCG, art. 2 LCCM). Estos preceptos, como señala PEINADO, «Introducción. Normas y ámbito de aplicación», Tratado de Derecho de cooperativas, t. I, cit. pp. 106 y s.), en ocasiones recogen expresamente el criterio cumulativo del domicilio social (LCG, LCLR), si bien esto no altera la situación respecto al resto, pues las restantes leyes exigen que la cooperativa que esté sometida a cada ley, fije su domicilio dentro del territorio de la respectiva Comunidad. 
dades Cooperativas de Canarias, que tenía prevista su aprobación a lo largo del 2015, aunque todavía no se ha aprobado.

Una cuestión esencial para saber cuándo es de aplicación una u otra norma, es determinar dónde desarrolla la cooperativa la actividad cooperativizada y, por ende, que se entiende por tal. El Reglamento del Registro de Sociedades Cooperativas (aprobado por el Real Decreto 136/2002), que delimita su ámbito de aplicación en función de que las cooperativas realicen principalmente su actividad cooperativizada en varias CC.AA., cuando no lo haga con carácter principal en ninguno de tales territorios (art. 2.1), con lo que sigue el criterio de la LCoOp, entiende por actividad cooperativizada: «la correspondiente a la actividad societaria por cualquiera de las formulas estables a que se refiere la Ley de Cooperativas, con independencia del domicilio social y de otras relaciones con terceros» (art. 2.2). El carácter interno de la actividad cooperativizada, se desprende también de las normas autonómicas utilizan las mismas palabras ${ }^{26}$ o expresiones similares (actividad societaria típica ${ }^{27}$, actividad intrasocietaria ${ }^{28}$, actividad societaria $\left.{ }^{29}\right)$, para indicar que la actividad cooperativizada se desarrolla internamente y que tiene un evidente carácter societario.

En realidad, la LCOOP tiene una aplicación muy residual, quedando como texto legal principal para la Comunidad Autonóma de Canarias (hasta que se promulgue su propia Ley, de la que ya hay un Proyecto de Ley) y para las ciudades autónomas de Ceuta y Melilla; y como ley subsidiaria y supletoria en el resto de CC.AA. para cubrir eventuales lagunas legales de las leyes autonómica, independientemente de que éstas contemplen dicha posibilidad. Fuera de estos casos, sólo sería de aplicación para las cooperativas que realizan su actividad cooperativizadas en varias CC.AA. y en ninguna con carácter principal, lo que es muy excepcional que ocurra y menos aún que se controle.

\section{La competencia estatal sobre las bases de la ordenación de la actividad crediticia y aseguradora}

No obstante, este reparto competencial entre el Estado y las CC.AA. sobre cooperativas, en el que la legislación del Estado tiene con carácter general el carácter de Derecho supletorio respecto de

\footnotetext{
26 Art. 1 LCEX, art. 3.1 LCCLM, art.2 LCLR.

27 Art. 1 LFCN.

28 Art. 2 LCCL.

29 Art. 3 LCAND, art. 1 LCIB.
} 
las CC.AA., resulta matizado en el caso particular de las cooperativas de crédito y de seguros, al tener el Estado reconocidas competencias exclusivas en la fijación de las bases de ordenación del crédito y la banca (art. 149.1.11. ${ }^{a}$ CE). En virtud de este precepto, el Estado promulgó la Ley 13/1989 de Cooperativas de Crédito (LCC), en el que fijaba, de acuerdo con determinadas resoluciones del TC, cuáles son estas bases en lo que se refiere a las cooperativas de crédito (disp. final $2{ }^{a}{ }^{a}$, cuyo contenido tiene aplicación preferente respecto a las normas autonómicas. En concreto, establece que las cooperativas de crédito se rigen por su ley específica y sus normas de desarrollo, sin perjuicio de las disposiciones que puedan aprobar las CC.AA. en el ejercicio de las competencias que tengan atribuidas en la materia; y por las normas que con carácter general regulan las actividades de las entidades de crédito; siendo de aplicación subsidiaria la legislación de cooperativas (art. 2 LCC).

En el caso de las cooperativas de seguros, las normas básicas estatales se contienen en la LOSSP (arts. 9.4 y 10.5) y en el ROSSP (arts. 22 y 23), aunque su interés práctico es mucho menor ya que no hay en la actualidad ninguna autorizada para operar como entidad de seguros.

\section{Bibliografía}

Arroyo, I.: Legislación sobre cooperativas, Tecnos, Madrid, 1992, 3. a ed.

BERCovitz , A.: «Sociedades de garantía mutua», R.D.M., 1975.

- «Antecedentes de la regulación legal sobre sociedades de garantía recíproca», en estudios de Derecho mercantil en homenaje al profesor Polo, Edersa, Madrid, 1981.

BORJABAD, P.: Manual de Derecho cooperativo, Bosch, Barcelona, 1993.

BROSETA, M.: La empresa, la unificación del Derecho de obligaciones y el Derecho mercantil, Tecnos, Madrid, 1965.

DIVAR, J.: La alternativa cooperativa: una respuesta ante la crisis, Ceac, Barcelona, 1985.

DUQUE, J., «Constitución económica y Derecho mercantil», en La reforma de la Legislación mercantil, Fundación Universidad-Empresa, Civitas, Madrid, 1979.

GARRIgues, J.: «Qué es y qué debe ser el Derecho mercantil», RDM, 1959.

GIRÓN, J.: «El concepto de Derecho mercantil», ADC, 1954.

LLoBregAt, M.L.: Mutualidad y empresas cooperativas, Bosch, Barcelona, 1990.

PAlÁ Berdejo, A.: «El Derecho mercantil y los caracteres de nuestro tiempo», Revista general de Legislación y Jurisprudencia, 1953.

PAZ-ARES, C., "Animo de lucro y concepto de sociedad (breves consideraciones en torno al artículo 2.2 LAIE)», en el Derecho mercantil de la CEE, en Estudios en homenaje a J. Girón, Civitas, Madrid, 1991. 
- «La causa no lucrativa en la agrupación de interés económico», en Escritos jurídicos en memoria de Luis Mateo, Tomo II, Universidad de Cantabria, 1993.

Polo, A., «Reflexiones sobre la reforma del ordenamiento jurídico mercantil», en los Estudios de Derecho mercantil en homenaje a Rodrigo Uría, Madrid, 1978.

RUBIO, J., "Sobre el concepto de Derecho mercantil», RDM, 1947.

VERGEZ, M., El Derecho de las sociedades cooperativas y su reforma, Civitas, Madrid, 1973.

- "Significado y encuadramiento de la sociedad cooperativa en el Derecho español», en Tribuna Cooperativa, núms. 40-41, 1980.

VICENT CHULIÁ, F., «Los órganos sociales de la cooperativa», RJC, 1978. 